\title{
Comorbidities on kidney transplantation waiting list relative to the status of the potential recipient
}

Jolanta Malyszko ${ }^{1}$, Teresa Dryl-Rydzynska², Wojciech Marcinkowski², Tomasz Prystacki², Jacek S. Malyszko 3

${ }^{1} 2^{\text {nd }}$ Nephrology Department, Medical University of Bialystok, Bialystok, Poland
${ }^{2}$ Fresenius Medical Care Poland, Poznan, Poland
${ }^{3} 1^{\text {st }}$ Department of Nephrology, Medical University of Bialystok, Bialystok, Poland

Submitted: 5 April 2016

Accepted: 29 April 2016

Arch Med Sci 2018; 14, 4: 941-944

DOI: https://doi.org/10.5114/aoms.2016.60337

Copyright (c) 2016 Termedia \& Banach

Kidney transplantation is the treatment of choice for most patients with end-stage renal disease (ESRD) [1, 2]. As patients with kidney disease often have significant comorbidities [3], the evaluation of a potential kidney transplant recipient should be as efficient and cost-effective as possible. The initial evaluation of the potential recipient should include a thorough medical, surgical, and psychosocial history and a detailed physical examination to identify comorbidities that could affect candidate survival after the transplantation. It should be stressed that a patient put on the waiting list for transplantation all the time is suffering from the same disease, and after waiting for the transplantation for several years it is not the same as it was at the moment of evaluation.

The aim of this study was to examine demographic and comorbidity factors of patients with end-stage renal disease on the kidney transplantation waiting list in regard to their status (active vs. temporarily disqualified).

The study was conducted on 300 potential kidney transplant recipients (40\% females) from 26 dialysis centers in Poland representing $9.7 \%$ of all dialyzed patients in these units. Enlisted patients were aged $49 \pm 13$ (35\% were < 50 years). Prevalence of hepatitis B (1.5\%) and C (3\%) was very low. The cause of end-stage renal failure was hypertensive nephropathy in $29 \%$, chronic glomerulonephritis in $29 \%$ and diabetic nephropathy in $25 \%$. Data analyzed were based on the clinical and laboratory parameters in the registration form for kidney transplantation.

Basal clinical and biochemical characteristics of the patients in the active and inactive group are presented in Table I. Blood types $B$ and $A B$ were more common in patients on the active list compared to the inactive list ( $28 \%$ vs. $13 \%, p<0.05$ and $5 \%$ vs. $1 \%, p<0.05$, respectively). Causes of end-stage kidney disease and prevalence of the most common comorbidities, i.e. coronary heart disease, chronic heart failure, hypertension and diabetes, were similar between the two studied groups. Similarly, hepatitis $B$ and $C$ were more prevalent in patients on the inactive list compared to the active list (3.0\% vs. $1.5 \%, p<0.05$, for both). Moreover, hypotensive drug treatment was used in a similar proportion in both groups, with calcium channel blockers being the most prevalent. Statin and acetylsalicylic acid were used in similar proportion in both groups ( $50 \%$ for statins and $48-49 \%$ for acetylsalicylic acid). Phosphate bind-

\author{
Corresponding author: \\ Prof. Jolanta Malyszko MD, \\ $\mathrm{PhD}$ \\ $2^{\text {nd }}$ Nephrology \\ Department \\ Medical University \\ of Bialystok \\ 24 a M. Skłodowskiej-Curie St \\ 15-276 Bialystok, Poland \\ Phone: +48 858317872 \\ E-mail: jolmal@poczta.onet.pl
}


ers, cinacalcet and native vitamin D, intravenous iron preparations and erythropoietin stimulating agents were used similarly in regard to frequency and doses. Vascular access modalities were also distributed similarly, with fistula being the most common and graft the least. Inactive status was due to several reasons: invalid (outdated) specialized consultations (70\%), treatment of hepatitis (5\%), intercurrent illness (9\%), recent cardiovascular disease (i.e. recent acute coronary syndrome

Table I. Clinical and biochemical data of patients on the active and nonactive waiting list

\begin{tabular}{|c|c|c|}
\hline Parameter & $\begin{array}{l}\text { Active list } \\
(n=235)\end{array}$ & $\begin{array}{c}\text { Nonactive list } \\
(n=65)\end{array}$ \\
\hline Age [years] & $50.62 \pm 20.64$ & $49.31 \pm 14.76$ \\
\hline $\mathrm{BMI}\left[\mathrm{kg} / \mathrm{m}^{2}\right]$ & $25.92 \pm 4.99$ & $25.64 \pm 4.36$ \\
\hline $\begin{array}{l}\text { Residual diuresis } \\
{[\mathrm{ml}]}\end{array}$ & $524(0 ; 1100)$ & $562(0 ; 100)$ \\
\hline $\begin{array}{l}\text { Dialysis vintage } \\
\text { [months] }\end{array}$ & $27(1 ; 168)$ & $35(1 ; 189)^{\star}$ \\
\hline Hemoglobin [g/dl] & $12.63 \pm 1.01$ & $10.99 \pm 1.11^{*}$ \\
\hline $\begin{array}{l}\text { Erythrocyte count } \\
{\left[\times 10^{12} / \mu \mathrm{l}\right]}\end{array}$ & $4.74 \pm 1.07$ & $4.39 \pm 0.93$ \\
\hline $\begin{array}{l}\text { Leukocyte count } \\
{\left[\times 10^{6} / \mu \mathrm{l}\right]}\end{array}$ & $7.49 \pm 1.05$ & $6.38 \pm 1.75$ \\
\hline $\begin{array}{l}\text { Platelet count } \\
{\left[\times 10^{12} / \mu \mathrm{l}\right]}\end{array}$ & $\begin{array}{c}214.02 \\
\pm 108.06\end{array}$ & $197.74 \pm 56.82$ \\
\hline AspAT [IU/I] & $17.58 \pm 13.41$ & $19.27 \pm 14.92$ \\
\hline AlAT [IU/I] & $17.23 \pm 9.48$ & $18.41 \pm 12.95$ \\
\hline Glucose [mg/dl] & $101.80 \pm 28.44$ & $102.81 \pm 27.00$ \\
\hline Cholesterol [mg/dl] & $179.36 \pm 63.13$ & $181.40 \pm 57.98$ \\
\hline $\mathrm{LDL}[\mathrm{mg} / \mathrm{dl}]$ & $152.62 \pm 60.09$ & $164.74 \pm 61.64$ \\
\hline $\begin{array}{l}\text { Systolic blood } \\
\text { pressure }[\mathrm{mm} \mathrm{Hg}]\end{array}$ & $128.11 \pm 18.37$ & $132.74 \pm 15.49$ \\
\hline $\begin{array}{l}\text { Diastolic blood } \\
\text { pressure }[\mathrm{mm} \mathrm{Hg}]\end{array}$ & $75.95 \pm 9.27$ & $78.06 \pm 7.51$ \\
\hline$E F(\%)$ & $57.32 \pm 15.15$ & $59.14 \pm 13.51$ \\
\hline LVdd $[\mathrm{mm}]$ & $42.97 \pm 11.48$ & $52.03 \pm 12.91$ \\
\hline IVS [mm] & $14.16 \pm 3.51$ & $15.27 \pm 5.61$ \\
\hline PTH [pg/ml] & $\begin{array}{c}496.98 \\
\pm 394.26\end{array}$ & $\begin{array}{c}525.66 \\
\pm 392.16\end{array}$ \\
\hline Creatinine $[\mathrm{mg} / \mathrm{dl}]$ & $10.20 \pm 1.55$ & $7.08 \pm 2.04^{*}$ \\
\hline $\begin{array}{l}\text { eGFR by MDRD } \\
{\left[\mathrm{ml} / \mathrm{min} / 1.72 \mathrm{~m}^{2}\right]}\end{array}$ & $8.10 \pm 3.60$ & $8.43 \pm 3.12$ \\
\hline Calcium $[\mathrm{mEq} / \mathrm{l}]$ & $4.34 \pm 0.31$ & $5.14 \pm 0.33$ \\
\hline Iron $[\mu \mathrm{g} / \mathrm{dl}]$ & $78.26 \pm 28.01$ & $80.56 \pm 37.93$ \\
\hline TSAT (\%) & $35.06 \pm 13.17$ & $36.15 \pm 15.47$ \\
\hline Ferritin $[\mu \mathrm{g} / \mathrm{l}]$ & $\begin{array}{c}606.70 \\
\pm 551.52\end{array}$ & $\begin{array}{c}664.28 \\
\pm 602.20\end{array}$ \\
\hline
\end{tabular}

with dual antiplatelet therapy) (6\%), recently diagnosed malignancy or additional diagnostic procedures (10\%).

We report the clinical characteristics of the potential kidney transplant recipients on the waiting list in Poland in regard to their status (active vs. nonactive). This is a real world scenario and also a representative sample size. According to healthcare payer requirements, should be not less than $7 \%$ of wait-listed and qualified patients in the dialysis center. Patients on the waiting list represent in general less than $10 \%$ of the population dialyzed. Inactive status is executed when an intercurrent condition develops that makes transplantation temporarily inadvisable, such as a treatable malignancy or infection. In Europe there are scarce published data on potential kidney allograft recipients in this regard. The percentage of wait-listed patients varied widely, ranging from $27 \%$ in the USA to $53 \%$ in the UK $[4,5]$; however, the precise methods of estimation are not given. Beuscart et al. [6] identified 7138 patients starting HD as the first renal replacement therapy between January 1 , 2002, and December 31, 2006. A total of 176 (2.5\%) patients were already wait-listed at the time of HD initiation, and 1392 (19.5\%) patients were wait-listed at the cut-off date, but the annual rate and/or prevalence at the certain time point (i.e. the end of the calendar year) were not provided. In another French study [7], on 8447 adult patients, aged 18-80 years, who lived and started dialysis in the 11 study regions during the inclusion period (2006-2008), 2498 (29.6\%) patients had been placed on the renal transplant waiting list by the end of 2012. The authors provided data on regional variations in the number of donors providing at least one organ, in the number of patients added to the waiting list, and in the number of kidney transplant recipients, but as above no prevalence of wait-listed patients was given. The same applies for USA data; in the OPTN/SRTR (Organ Procurement and Transplantation Network/ Scientific Registry for Transplant Recipients) the number of wait-listed patients is given [8], while in the USRDS (United States Renal Data System) the number of kidney transplant recipients is given [9]; thus the rough estimate of the percentage of wait-listed patients is below 20. In the USA in 2013 , the most common reasons for inactive status among newly registered patients included incomplete work-up (74\%), too sick (8\%), insurance issues (7\%), weight inappropriate for transplant $(5 \%)$, too well ( $2 \%$ to $3 \%)$, and candidate choice (1\% to $2 \%$ ) [8]. Our data are in agreement only in regard to incomplete work-up. Most adult CKD patients who are being evaluated for transplantation undergo some form of cardiovascular screening at the time of initial evaluation and pe- 
riodically during the wait-list period. However, it is not clear whether screening asymptomatic patients prior to transplantation provides any benefit or which method of screening is optimal [10]. The prevalence of diabetes in the USA is two-fold higher than in Poland. Diabetes is the major cause of ESRD, but also bears a risk of other complications, including cardiovascular ones [11]. Several guidelines have been published on the evaluation of potential kidney transplant recipients [12, 13]. In 2014 two guidelines, at least partly relevant to the cardiac evaluation of potential kidney transplant recipients, were published $[14,15]$. The major breakthrough is in the part devoted to surgery in patients on dual antiplatelet therapy. From the clinical perspective, in a case of urgency for transplantation, i.e. lack of vascular access, patients do not need to be kept inactive on the waiting list due to dual antiplatelet therapy [15]. In addition, some patients, in particular with diabetes, may require either percutaneous coronary intervention ( $\mathrm{PCl}$ ) or cardiac artery bypass grafting (CABG). Thus as reviewed previously, cardiovascular evaluation of potential kidney allograft recipients is of utmost importance [16]. A meta-analysis suggested that the strategy of CABG is better than PCI with DES for diabetic patients with multivessel CAD [17].

Our patients have shorter dialysis vintage than in the USA, where in 2013, nearly $30 \%$ of candidates on the waiting list had been on dialysis for more than 6 years; approximately $10 \%$ had been on dialysis > 11 years [8]. In our population the median time to transplant for new candidates was 3 years, while in the USA it was more than 4.5 years for candidates listed in 2009 (indicating the number of days by which $50 \%$ of these patients have been transplanted) [8].

It should be stressed that prevalence of hepatitis B and/or C in Poland is very low, similar to that in the general population in the world [18] as well as in Europe [19]. The prevalence of HCV is known to be higher in HD patients (CKD stage 5D) than in the general population, although there is heterogeneity of prevalence depending on the dialysis unit studied and associated with increased mortality [20]. According to our study, the temporal suspension on the waiting list is mainly due to the lack of required consultations or outdated consultations in the vast majority of patients. Upon input of the necessary data, patients are wait-listed again. A minority could be temporarily disqualified due to recent malignancy or other recent serious illness. Our study is comprehensive for wait-listed patients and representative for the dialyzed population in Poland. With the expansion of the donor pool including living related donors or even altruistic donors, our waiting list could be even shorter. We should emphasize the need for timely preparation of all necessary diagnostic procedures, laboratory examinations, and consultations for better care of our potential kidney transplant recipients and give them a chance for kidney transplantation in the shortest possible time in the best clinical condition.

In conclusion, kidney transplantation is available only to a minority of the dialyzed population mainly due to significant comorbidities. Inactive status is temporary and mainly due to lack of required consultations. Our data indicate the scale of the task ahead of nephrologists to increase the number of potential kidney transplant recipients, offering them the best possible form of renal replacement therapy.

\section{Conflict of interest}

The authors declare no conflict of interest.

\section{References}

1. Suthanthiran M, Strom TB. Renal transplantation. N Engl J Med 1994; 331: 365-76.

2. Wolfe RA, Ashby VB, Milford EL, et al. Comparison of mortality in all patients on dialysis, patients on dialysis awaiting transplantation, and recipients of a first cadaveric transplant. N Engl J Med 1999; 341: 1725-30.

3. Franczyk-Skóra B, Gluba A, Olszewski R, Banach M, Rysz J. Heart function disturbances in chronic kidney disease - echocardiographic indices. Arch Med Sci 2014; 10: 1109-16.

4. Szeifert L, Bragg-Gresham JL, Thumma J, et al. Psychosocial variables are associated with being wait-listed, but not with receiving a kidney transplant in the Dialysis Outcomes and Practice Patterns Study (DOPPS). Nephrol Dial Transplant 2012; 27: 2107-13.

5. Pruthi R, Curnow E, Roderick P, Ravanan R. UK Renal Registry $17^{\text {th }}$ Annual Report: Chapter 11 Centre variation in access to renal transplantation in the UK (2008-2010). Nephron 2015; 129 Suppl 1: 247-56.

6. Beuscart JB, Pagniez D, Boulanger E, Duhamel A. Registration on the renal transplantation waiting list and mortality on dialysis: an analysis of the French REIN registry using a multi-state model. J Epidemiol 2015; 25: 133-41.

7. Bayat S, Macher MA, Couchoud C, et al.; REIN Registry. Individual and regional factors of access to the renal transplant waiting list in france in a cohort of dialyzed patients. Am J Transplant 2015; 15: 1050-60.

8. Matas AJ, Smith JM, Skeans MA, et al. OPTN/SRTR 2013 Annual Data Report: kidney. Am J Transplant 2015; 15 Suppl 2: 1.

9. http://www.usrds.org/adr.aspx Accessed: April 26, 2016.

10. Lentine KL, Costa SP, Weir MR, et al. American Heart Association Council on the Kidney in Cardiovascular Disease and Council on Peripheral Vascular Disease; American Heart Association; American College of Cardiology Foundation. Cardiac disease evaluation and management among kidney and liver transplantation candidates: a scientific statement from the American Heart Association and the American College of Cardiology Foundation: endorsed by the American Society of Transplant Surgeons, American Society of Transplantation, and National Kidney Foundation. Circulation 2012; 126: 617-63. 
11. Papaetis GS, Papakyriakou P, Panagiotou TN. Central obesity, type 2 diabetes and insulin: exploring a pathway full of thorns Arch Med Sci 2015; 11: 463-82.

12. Kidney Disease: Improving Global Outcomes (KDIGO) Transplant Work Group. KDIGO clinical practice guideline for the care of kidney transplant recipients. Am J Transplant 2009; 9 (Suppl 3): S1-157.

13. ERBP Guideline on the Management and Evaluation of the Kidney Donor and Recipient. European Renal Best Practice Transplantation Guideline Development Group. Nephrol Dial Transplant 2013; 28 Suppl 2: ii1-71.

14. Authors/Task Force members, Windecker S, Kolh P, Alfonso F, et al.; Authors/Task Force members. 2014 ESC/ EACTS Guidelines on myocardial revascularization: The Task Force on Myocardial Revascularization of the European Society of Cardiology (ESC) and the European Association for Cardio-Thoracic Surgery (EACTS) Developed with the special contribution of the European Association of Percutaneous Cardiovascular Interventions (EAPCI). Eur Heart J 2014; 35: 2541-619.

15. Authors/Task Force Members, Kristensen SD, Knuuti J, Saraste A, et al.; Authors/Task Force Members. 2014 ESC/ESA Guidelines on non-cardiac surgery: cardiovascular assessment and management: The Joint Task Force on non-cardiac surgery: cardiovascular assessment and management of the European Society of Cardiology (ESC) and the European Society of Anaesthesiology (ESA). Eur Heart J 2014; 35: 2383-431.

16. Małyszko J, Bachorzewska-Gajewska H, Tomaszuk-Kazberuk A, Matuszkiewicz-Rowińska J, Durlik M, Dobrzycki S. Cardiovascular disease and kidney transplantation-evaluation of potential transplant recipient. Pol Arch Med Wewn 2014; 124: 608-16.

17. Qi X, Xu M, Yang H, et al. Comparing mortality and myocardial infarction between coronary artery bypass grafting and drug-eluting stenting in patients with diabetes mellitus and multivessel coronary artery disease: a meta-analysis. Arch Med Sci 2014; 10: 411-8.

18. Mikolajczyk AE, Aronsohn Al. Current management of chronic hepatitis $B$ and $C$ in chronic kidney disease. Adv Chronic Kidney Dis 2015; 22: 352-60.

19. Baid-Agrawal S, Pascual M, Moradpour D, Somasundaram $R$, Muche $M$. Hepatitis $C$ virus infection and kidney transplantation in 2014: what's new? Am J Transplant 2014; 14: 2206-20.

20. Baid-Agrawal S, Schindler R, Reinke P, et al. Prevalence of occult hepatitis $C$ infection in chronic hemodialysis and kidney transplant patients. J Hepatol 2014; 60: 928-33. 